\title{
Unequal education opportunity in Pakistan for rural and urban areas and its evolution
}

\author{
Arshad Muhammad Umer \\ Inner Mongolia University
}

\begin{abstract}
Since independence, with the expansion of the scale of Pakistani's education, the level of education, urban and rural residents have been improving year by year. Still, the educational inequality problems have not been effectively solved. The survey of the last two decades shows the influence of education, household registration, family, social and economic status, parental education, several brothers, and sisters, has been evaluated on three factors high school, college, and university. The study found that the high school entrance opportunity differences in urban and rural areas have not been changed, technical college, college or university entrance opportunity between urban and rural areas have potentially expanded, father's occupational status affects children's education, but other factors remain same. The study shows that since 1981 no obvious change in unequal educational opportunities, the other rising trend in educational inequality due to the different number of brothers and sisters. The study shows that after the independence of Pakistan, the education structures and evolution of inequality should be focused on people's micro mechanism of education decisions.
\end{abstract}

Keywords: rational action theory, culture capital, educational stratification or policy, Pakistan education inequality

\section{Introduction}

Equal access to education is every human's basic right, and everyone should have the same opportunities. Everyone has equal rights, so no one should be discriminated against the teaching because of gender, social background, religion, age, or economic issues. Since independence, with the expansion of the scale of Pakistani's education, the level of urban and rural residents has been improving year by year. Still, the educational inequality problem has not been effectively improved. In recent years the department of education has been noticed this issue. In Pakistan, children do not have proper access to basic education because of inequalities that initiate in sex. Corruption and poverty often hamper educational opportunities. According to Article 25-A (Right to education), the state shall provide free and compulsory education to all children of the age of five to sixteen years in such a manner as may be determined by law ${ }^{[1]}$. But in the last few years wealth and income inequalities have increased in Pakistan so Pakistan is divided into more socioeconomic lines, the inequality in education has been more increased. Low-income families do not have enough resources to pay for school fee, books, and uniforms. The current research has two main lines about Pakistan's education stratification. Online discussed about the system, market transition and the relationship between education stratification. Marketization has changed in the Pakistan society to the hierarchical system, so the education inequality changed. The education gap is in expanding trend of Pakistani resident since the market transition has changed. Another factor that influences education inequality in Pakistan is mainly guided by maximizes maintains inequality theory. Most research result, supports the MMI theory in Pakistan; that's why, Pakistan's education did not cause the education class differences toward the narrow sides, there are even expanding trend.

The author thinks that existing research only to understand Pakistan's education inequality and its change and provides a rich theoretical experience. But during research, most research focus on the impact of the class or class of inequality or discuss the institutional change in education. And didn't pay the proper attention on consequences like that, the micro process of individual or family's decision of education is not always perfect, Since the independence of Pakistan and its opening the population is increasing as well as, the scale of education is also expanding, the policies also major reform and adjustment. Because of the changes in policies or adjustment in most education resources, adjustment, and allocations of educates, admission, and graduation, distribution system needs a lot of expenses, so it directly affects the individual or family. Family education decisions are also related to it. Therefore, the change in education policy may directly influence the individuals and their families, micro-level education, making process; thus, it is the crucial cause of inequality education structure. The research shows since independence and opening education inequality, in addition to discuss the relationship between class education 
inequality and change in policy, still need to pay attention to education and related factors of education to obtain the change in social policy (especially the microcosmic factor) influence, this is also the main purpose of this article.

\section{The Micromechanics of Individual or family education decision: \\ Although most scholars of education stratifications are concerned about the education class inequality and its historical evolution, many scholars are still concerned about the micro-level study, individual education differences or family education decision-making process. Here involves three most representative theories, culture capital theory, resource dilution theory and education, the strategy of rational action theory.}

\section{Culture capital theory:}

Cultural Capital is an essential concept in the Bourdieu theory system, according to Bourdieu's point of view, culture capital theory has three primary forms, one is a physical form, its deep-rooted in the body or the mind's temperament tendency, Second is objective form, embodied in culture items such as pictures, books, dictionaries, and other learning material etc., third is an institutionalized form or can be referred to culture system. Bourdied and his colleagues found in the study, (P. Bourdieu) "how to improve the students, cultural capital cognitive abilities and learning skill, how to get better grades, in addition the article finds that the rich families because of culture resources have better culture atmosphere ${ }^{[2]}$, this can increase the negativity or desire aspiration in children. Therefore, culture capital and education have a very strong relationship, if the cultural capital is strong, then the schools have good performance, there is more students have the opportunity to enter in school". (P.Bourdieu J.C.Passeron) "Culture regeneration production theory" this theory is used to explain the education class ${ }^{[3]}$. According to the cultural capital theory upper class used more resources to identify and maintain its elite culture symbol of the identity and status, help the children to succeed in the school education and to maintain their elite status". (P.Bourdieu) "the culture capital has the direct relationship between family background and education mechanism. Because of the emphasis on education for the microscopic process, culture capital theory helps to understand the social class and education so it's widely attention in the field of social stratification and the sociology of education". After study lot of empirical research support based on Western society, Based on empirical researches result proved that Pakistan's society and teaching education have a close relationship between cultural capital theory.

\section{Resource dilution theory}

Resource dilution theory is about the theoretical assumption; it's the relationship between siblings and obtaining educational resources. (J. Black) "according to research on adults, if someone has more brothers and sisters than they have lower levels of education, for those students, the number of brothers and sisters, and their academic performance is inversely proportional to the educational expectation" To explain the phenomenon of the resource dilution model is that "Increasing number of brother and sister in a family, each child have to share the family resources, thus have a negative impact on each child's education" (J black) "family resource include three aspects. First one on the family circumstances or scenarios, its effect on household necessities, as well as the cultural items, such as books, music, etc., Second there are various benefits access to children from the social world like social opportunities, third one is attention of parents toward kids, intervention or direct teaching. In the research of dilution theory, on the number of empirical studies based on American society were further validated. Studies shows that approach is also applicable in Pakistan, the number of brothers and sisters shouldn't be ignored, these are essential variables, and there is no article or policy in the constitution of Pakistan to control the population.

\section{Rational action model of educational decision making}

The rational action model of educational decision-making originates from the reflection and criticism of MMI theory, although many empirical data support the MMI theory and its assumptions. But according to European researchers in many countries, the actual situation and its theoretical presupposition are not consistent. (Richard Breen and J.H.Goldthorpe) For example, in different countries, such as Germany, Netherlands, Sweden and so many others, inequality of education in class is potentially in a declining trend. According to the micro process brain and some other factors proposed to study of educational inequality ${ }^{[4]}$. A researcher thinks that individuals and his family have to decide if they should continue the education on a rational basis, like education cost and its benefits; according to this sensible choice, the mode of mathematics, analysis on the micro-level of individual education making decision process. According to this model to explain the class difference and evolution of education, an individual have personal choice, should the person continue the study or not on the basis of three different elements, one is the cost of school fees, including tuition fee, books, and cost of living, the second one is the probability of successful entrance school homework, the performance of test scores, and other criteria to decide whether he should go to school or not, the third one is value or utility, should he continue to read or enter to labor market, the theory have a different effect on the different classes, have different elements and different three mechanisms leading to education according to his class, the first one is relative risk aversion mechanism. Education is an essential factor of status. The highest class taught their kids in traditional schools to maintain their class position; otherwise, there is a risk of downward mobility, and the lowest class people, if 
they don't continue the study, can lose the chance of upward mobility. Still, they don't have the risk of flowing downward. Therefore the upper-class group has higher driving force, so they choose to continue their education. The second element is the ability and success mechanism, the higher class of children have a solid ability to learn and have higher expectations of success because education have a filtering function so higher class are more likely to win success. The third factor is the difference of resource mechanism. The higher class can provide more resources to children, relatively low class, and therefore the higher classes have a greater chance to continue studying. The theory summarizes that the change of three elements impacts education decisions, has less effect on higher class groups, and has the more extensive influence of the lower class ${ }^{[6]}$. For instance, if the cost of education, strength of education, screening function, or continue or leave study on the effect of less participate in the work of utility, so the lower-class groups are more likely to quite an education, it increases the order of education layer of inequality, on the other hand education inequality drops.

\section{Analytical framework of the study}

This research is going to explore the microscopic factors influence on Pakistan resident education decisions. The three theoretical perspectives are essential for the references, although these three theories are respectively, have different angles to analyze the education inequality, but the purpose is common. These theories focus on individual or family education on the micro decision-making process and containing some specific similar elements. For example, in the theory of cultural capital and resource, family endowment source is similar; culture capital theory stresses the relationship between culture capital and the individual learning ability. In certain extend and the rational action theory focuses the relationship between ability and expectation of success mechanism. In addition, the resource dilution theory emphasizes the distribution of limited educational resources of a family between the numbers of children. This is the common resource differential mechanism in the rational action theory. Based on the inherent relation among the three theories, the author thinks that they can be integrated, the cultural capital and resource dilution mechanism on the rational action model framework is analyzed, and in order to understand the Pakistan society of education inequality and its historical change. Specifically, according to the rational choice model culture capital and the number of children, two mechanisms are operational indicators. Another mechanism of rational action model is the relative aversion mechanism "emphasizes the risk aversion consciousness of class differences, therefore we can use class or stratum categories like occupational status as an index of operationalization" In addition, because Pakistan's urban and rural differences of caused by different household register identity is a significant indicator of layered, at same time professional status and household register identify as a class of operational indicators. The Conclusion is that the study about rational action theory under the framework of the number of test classes, household registration, culture capital, number of brothers and sisters, and several other factors affect education. When emphatically discussing and focusing on expanding education, education policy, and macroeconomic structure changes. Then these factors will be changed.

\section{Research hypothesis}

The Changes in Pakistan's education policies and their impact on the educational attainment of education

Since independence and it's opening up in the education policies of Pakistan have been some significant changes and adjustments. The main changes held in education policies (a) in the first national education conference (b) in 1959 the national commission was established (c) in 1969 new education policy (d) 1973 article 37 B (e) in 1992 education policy was announced by federal minister of education in Islamabad (f) change the education policy in March in $2007(\mathrm{~g})$ national plan of action for EFA ${ }^{[7]}$.

Overall, the change of educational policy in Pakistan is mainly focused on elementary education which is compulsory, and it will be free provided by the state, second one new education policy was shafted to scientific, technical and vocational educational institutes for middle level skilled workers, third one encouraging the private sector in education. (Department of Education) According to the white paper, "The education system should raise highly knowledgeable, skillful, productive, creative and confident individuals who have advanced reasoning and perception of problem-solving skills; are committed to democratic values and human rights; are open to new ideas; have a sense of personal responsibility; are committed to moral values; have assimilated the national cultures; can tolerate differences in opinion, faith, and culture; have empathy towards all of humanity; and can participate in the productive activities in society for the common good using Social and Physical Sciences and Technology ${ }^{[8]}$."

Government Official decides to provide free secondary school education to everyone, but the government schools are not well facilitated; teachers often to leave, don't have electricity, chairs, stationery items, or libraries. So, people move toward the private education system, which is more expensive, a common school tuition fee average per person per year is 3600- $24000 \mathrm{Rs,} \mathrm{college} \mathrm{and} \mathrm{the} \mathrm{University} \mathrm{education} \mathrm{tuition}$ average per person per year from 40000 to $200000 \mathrm{Rs}$, add the rising cost of accommodation, living expenses, books and utility expenses of higher education to become have burden for many low-income families ${ }^{[9,17]}$. In addition, to the above 
policy, regulation of education system changes, the First government starts a free education expansion policy is a direct result of the college enrollment increased more than $30 \%$ to $2008{ }^{[13]}$. The gross enrollment rate reached more than $45 \%$, another important issue is the implementation of policies in rural schools, namely to resources. Main focus on urban schools, so rural ordinary school showed a trend of the sharp decline in the number of schools, because the rural students go to the urban school it increases the distance, for rural students in urban school have to pay high tuition cost, cost of accommodation, meal and so on, this has a direct effect on the rural student's access of high school education ${ }^{[10,11]}$.

In addition to changes in policy of industrial structure and changing in labor market structure also noteworthy, especially after the start, trading with China, the Chinese industrial structure gives priority to the manufacturing, the cause of the development of third-party industry, an industrial economy is going toward down trend, so its decrease in blueand white-collar job, for the college and university students, this situation may also affect the individual education choice. According to the education decision-making model of rational action theory, change in education policy and change in macroeconomic structure has changed the individual education decision, which refers to three main elements, education cost, probability of success, and utility of claim ratio, which will change the mode of education choice, different groups lead to change in the structure of educational inequality, cause of policy change, cause by the implication result on different education level have different education inequality. Due to implementation of the compulsory high school education and most of them don't need to pay cause of public welfare, so according to the writer's opinion in high school level inequality of education will be on a declining trend, therefore assumed some hypotheses:

Hypothesis 1a: Inequality in High school entrance opportunity will gradually be on a declining trend.

Hypothesis 1b: Inequality in High school entrance opportunity will gradually be in the declining trend in both rural and urban areas.

Hypothesis 1c: Family socioeconomic status will less effect on high school admission class inequality opportunity.

Hypothesis 1d: As a result of family cultural capital difference, the high school entrance opportunity inequality will be in a declining trend.

Hypothesis 1f: Number of siblings will not effect, so the entrance opportunities in high school level inequality will be on decline trend.

There is the main difference between high school and college, high school education is very cheap or free under the Punjab education foundation, but for colleges and universities have to pay the fee and have passed the entrance exam. Even in college and university screening system is not good enough, but for university and college tuition fee and living expenses increased significantly, but as compared to find a job is $\mathrm{s}$ difficult task for university graduates, and wages fall in the result of declining in college enrollment because they are going to participate in labor, so expect high school, college educational stage entrance opportunity inequality may appear upward trend, therefore assumed some hypothesis:

Hypothesis 2a: College admission opportunity inequality is on a rising trend.

Hypothesis $2 \mathrm{~b}$ : College entrance opportunity rising inequality between urban and rural areas.

Hypothesis 2c: cause of family socioeconomic status the college class of entrance opportunity inequality rising trend.

Hypothesis 2d: College entrance opportunity because of difference in culture capital rising inequality.

College entrance number of sibling will negative effect, should be increase the inequality.

Hypothesis 3a: at university education stage entrance opportunity inequality is on a rising trend.

Hypothesis 3b: at university entrance opportunity rising inequality between urban and rural areas.

Hypothesis 3c: cause of family socioeconomic status the rising trend of college class of entrance opportunity inequality.

Hypothesis 3d: University entrance opportunity due to difference in culture capital rising inequality, the influence of culture capital with improved.

Hypothesis 3e: Number of siblings will affect the university entrance education opportunity and increase the inequality.

\section{Data, Variables, and methods}

The study used data from center of World Bank, GPA scores, test scores, drop-out rates, school passageway insights, and school finishing rates, using multi-stage random sampling method. During the general survey of urban and rural area in Pakistan take a sample of 3000 people, urban and rural area of the sample size of 1991 and 1009 respectively ${ }^{[12]}$, detailed information data collected about the respondent education experience, as well as the study of respondents believes family background and interest, this paper focuses only on those likely to high school, college, technical, vocational college, and the university, the description of the effective 


\begin{tabular}{|c|c|c|c|c|c|c|}
\hline \multicolumn{7}{|c|}{ Table 1} \\
\hline \multirow{2}{*}{ Variable } & \multicolumn{2}{|c|}{ High school student } & \multicolumn{2}{|c|}{ College student } & \multicolumn{2}{|c|}{ University student } \\
\hline & Mean & standard deviation & Mean & S.D & Mean & S.D \\
\hline whether the entrance & 0.4285 & 0.175 & 284.5 & 0.2475 & 0.2 & 0.245 \\
\hline Histiry before Entrance & - & & & & 0.1335 & 221.5 \\
\hline Urban Area & 0.4635 & 0.13 & 0.4705 & 0.1185 & 0.4725 & 0.1135 \\
\hline Male & 0.2375 & 0.2495 & 0.248 & 0.25 & 0.2615 & 0.2495 \\
\hline Rural Area & 0.2985 & 0.2455 & 0.267 & 0.2495 & 0.172 & 0.2375 \\
\hline Father's status ISEI AGE 16 & 17.175 & 8.355 & 17.905 & 8.7 & 19.68 & 9.16 \\
\hline Parent's Education & 3.8035 & 2.163 & 3.9625 & 2.667 & 4.4375 & 2.213 \\
\hline Number of sibling & 1.1195 & 0.8655 & 1.0965 & 0.8575 & 0.943 & 0.806 \\
\hline \multicolumn{7}{|l|}{ Historic Stage } \\
\hline $1980-1990$ & 0.2615 & 0.2495 & 0.2115 & 0.247 & 0.1145 & 0.229 \\
\hline $1991-2000$ & 0.1445 & 226.5 & 0.175 & 0.2385 & 0.169 & 0.2365 \\
\hline $2001-2010$ & 0.094 & 0.1955 & 0.1135 & 0.2095 & 0.1815 & 0.2405 \\
\hline Sample Size & \multicolumn{2}{|r|}{1531} & \multicolumn{2}{|c|}{1463} & \multicolumn{2}{|c|}{887.5} \\
\hline
\end{tabular}

sample size of each education stage and variable system shown in table 1.

The purpose of data analysis is the inspection of high school, college and University, Including Arts, science, commerce, and technology field, influence factor of the three education levels of entrance opportunities, there are different variations accordingly virtual variable, (a) all students who went to high school, whether to enter college stage or not (b) all student who went to college, whether they enter to university or not, according to research, the independent variables of this study include the entrance historical stage, father's occupation, status, culture capital, and number of brother and sisters. Relevantly independent explained as follows,

(a) Entrance of the historical stage, according to survey data the educational information of respondents in detail, including each learning phase of the staring time, so each respondent can get enters a high school education level and his graduation time period, in this paper the analysis, combined with the change of education policies in Pakistan, the distinguish the three historical stages, from 1981- to 1990, from 1991 to 2000 , from 2001 to 2010 ,

(b) The registered permanent residence, In Pakistan, there is a lot of difference between urban and rural education resources, so the household reside affects one, In addition, most of the rural area students after admitted to university stay at city and work there. Therefore, not only to distinguish the surveyed data acquisition of household register, and consider the entrance in front of household register, so during the survey, the respondents asked whether experienced Urbanized, type and time, thus can be judged of each education household register before the stage entrance.

(C) The father's occupational status, according to the practice, during the research study used the respondent's occupational status of father, when he was 16 years old, family economic status, or measured the class status, because 16 year age is a critical age, at this time the family situation is particularly important for children's education. During the survey, record the professional type of respondents and their family members according to the 1988 (ISC088) International standard. (H.B.G Ganzeboom ,P.M.De Graaf and D.J Treiman) Standard international occupational social and economic status index (ISEI),it is a continuous variable, which is between 100 and 0 . Using the ISEI value measure as an occupational status, its linear assumption, and the index's stability. In detail tried to use the professional category management class, technology, staff, industrial workers, and farmers) in place of its statistical estimation, the estimated two ways were found, but the results are consistent. To explain and take into account the readability of the form, the author insists on using this index.

(D) Culture capital, research the educational level of the parents as measurable indicators of the social economic status of family, parental education years (especially after father control socioeconomic status variables) is important indicators of family's culture capital, because with a higher education degree of parents can often provide more cultural capital for the children, the more cultural items (books, newspapers, etc.) and better cultural environment and learning atmosphere, thus helping to improve children's learning ability and educational aspirations. In this study, the use of parental education in the two sides of the higher education period as a measure of this variable.

(E) Sibling, during the survey, asked to respondents rang of number of brothers and sisters, ranging between 0 to 12 , In the statistical analysis, in case of more the 6 number of sisters and brothers then assigned the 6 , to reduce the extreme rare influence of values on the model estimates. Considering the 
education of gender inequality is an important part of education stratification research, so all the statics in the model to control the gender variable males $=1$, in addition, most of the rural area, economic development level and the education condition is relatively backward, so all models 1 joined by the urban students and the other 0 model joined by the rural students as a control student.

Because of the dependent variable is 0 and 1 , so does the reference to MEL entrance model (R.D Mare) Logistic response model of school continuation, according to the model revision, first of all comparing by different birth cohort by MEL, the difference between to explore the change of education stratification, the study directly compares the entrance of the different historical stages, thus it can be more accurately estimate the change in historical trend, Second, MEL modeling the same period for each group respectively, after that simply compare the coefficient of type size of each module, the disadvantage of this approach inspection is not significant of different size of coefficients, this study will not be together with the historical period of the sample, as the independent variables into the model and the historical period, and the trough the calculation the interaction effect of each variable and historical period to the strict inspection whether the historical volatility of each variable effect significantly or not. In short, the revised model is more rigorous and more conducive to answering this study's question.

\section{Result of Data Analysis}

The author respectively describes the impact of factor by Statistical estimation on the high school, college, and university entrance opportunities. For each entrance phase, first establish a non-interactive model to examine the net effect of the variables, and then add the interaction terms of the main variables and enrollment period, to test their effects in different periods to observe significant change.

Unequal educational opportunities of high school and its evolution

Table 2 shows the estimation result of high school admission, Model 1 shows that enrollment history in high school is significantly in a rising trend, Historical period from 1981 to 1990

compared to the period from 1991 to 2000 in high school the enrollment in a rising trend, probably $43 \%\left(e^{0.307-1=0.424}\right)$ but from 2001 to 2010 it increased more than 2.6 times ,$\left(e^{0.498}=1.354\right)$, High school entrance Urban areas, Gender difference, overall higher education opportunities for Urban Areas were higher than the rural areas, men's have higher education opportunities than women. The difference is greater between urban and rural areas, after control other factors, the entrance rate of rural residence is probably $34 \%$ ( 1 $e^{-0.610}=0.337$ )lower than that of urban citizens. When father's occupation status is higher, then the entrance opportunity to school is bigger for further study, study shows that the higher class has more chance to enter into high school. Besides, parental education is more elevated, having the positive significant effect on the children entrance high school opportunities. The result proves that if cultural capital is higher in the family, there is a more apparent advantage to their children. Finally, the role of siblings has a negative effect on the individual's education. Increasing the number of brothers and sisters have lower chance for individuals to receive the education.

Model 2 of table 2 estimated the interactive effect on domicile/register household and historical stage. It shows coefficient of two interactive items both doesn't have statically significance, also shows that after the independence in a different historical period, the degree of unequal education opportunities between rural and urban areas has no substantial changes, in other words, urban and rural area students both enjoy the benefits of compulsory education. Educational opportunities not consistent with the declining trend in urban and rural areas, so assumption 1Ais not verified.

From Model 3 table 2 Father Status's ISEI and historical stages of the two interactive coefficients are not significant, during 1981 to 2010 occupation, position of father, family status, hasn't substantial changes on the effect of entering high school, so assumption 1B is not confirmed.

Table 2 model 4, length of parental education have positive effect on the entrance to the high school, which significantly increased (parental year of education and historical stage are two positive interactive coefficients with significant), after controlling other factors, from 1981 to 2010, schooling of parents increase one year, then the opportunity for the children increase $6 \%,\left(e^{0.058_{-1}=0.061}\right) \quad$ however from 1991 to 2000 increased up to $10 \%\left(e^{0.058+0.33_{-1}=0.098}\right)$. From 2001 to 2010 it increased to $20 \%\left(e^{0.058+0.11_{-1=.20}}\right)$.

This reflects the culture of the capital, and parental education is playing more important role in Children's education, in other words, the children who are lack of family cultural capital probably have more chance to lose the education. This result is contrary to the assumption $1 \mathrm{C}$, this assumption is just opposite.

Table 2 model 5, the interaction between number of brother and sisters and the historical period from 1991 to 2000 are not significant, which indicates that the effect of this variable has changed before 2001, but from 2001 to 2010 interaction effect is substantial, and its harmful, this shows that after 2001, the number of siblings in high school entrance has a significantly 
Unequal education opportunity in Pakistan for rural and urban areas and its evolution

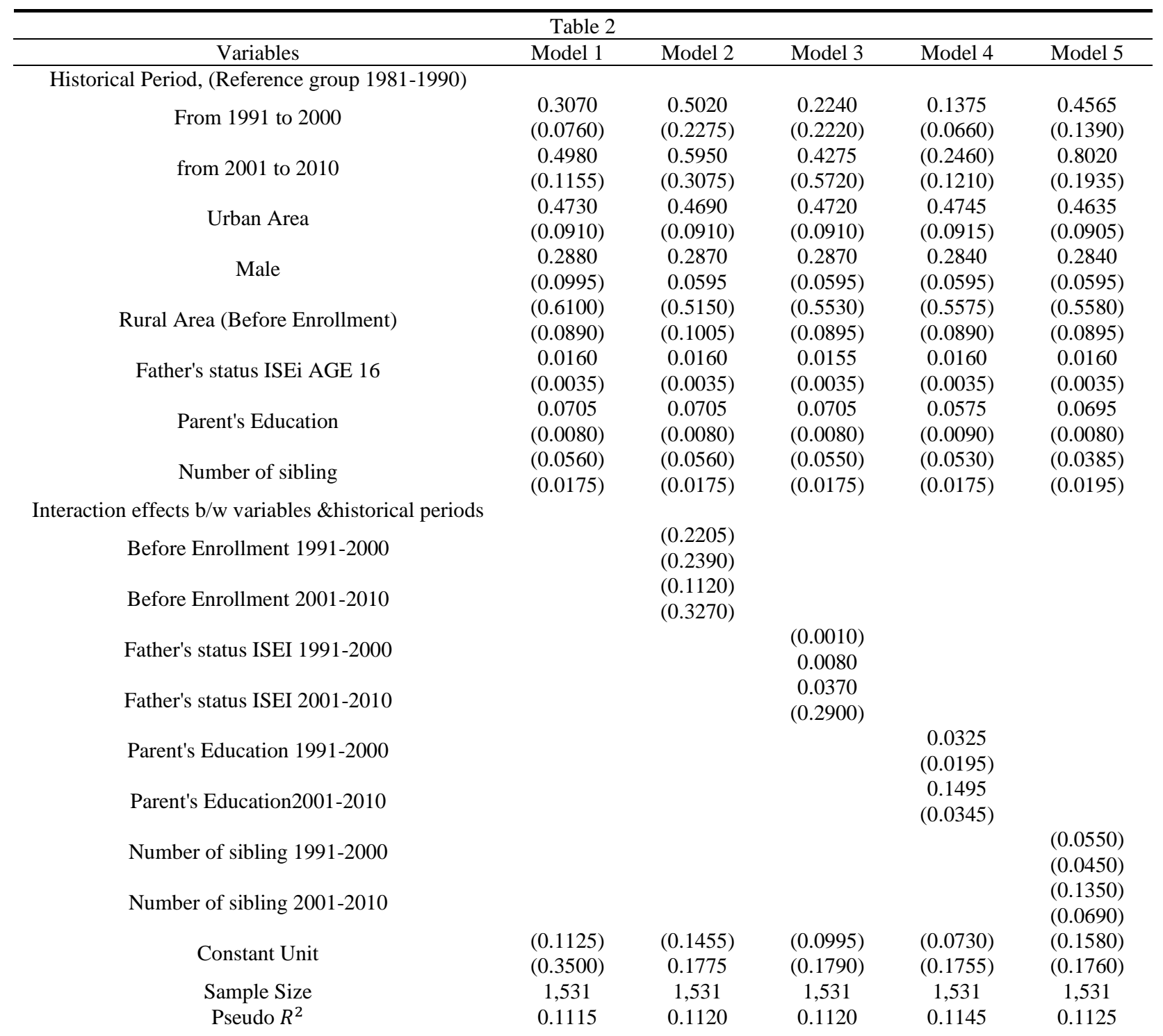

negative effect as compared before 2001. From 1991 to 2000 each additional number of brother and sister, entrance opportunity fell $3.5 \%\left(1-e^{-0.039=0.037}\right)$. From 2001 to 2010 when the increase on sibling, then lead to entrance opportunity has dropped $15 \%\left(1-e^{-0.039-0.139=0.14}\right)$. This shows that with time in the large families the opportunities for entering high school didn't improve, even get worse, so the assumption 1D are not confirmed.

In short, result of table 2 shows in the aspect of entering high school, there is no change in inequality of education in urban and rural areas, but because of family culture capital and number of sibling inequality is going to upward trend after 2001.this suggests, even compulsory education popularization gradually and eventually realize the public welfare, but didn't get the expected result, in high school admission opportunity in equality between different groups.

\section{Unequal educational opportunities for college and its evolution}

Table 3 shows the statistical estimation result of inequality in college admission opportunities. 
Unequal education opportunity in Pakistan for rural and urban areas and its evolution

\begin{tabular}{|c|c|c|c|c|c|}
\hline \multicolumn{6}{|c|}{ Table 3} \\
\hline Variables & Model 1 & Model 2 & Model 3 & Model 4 & Model 6 \\
\hline \multicolumn{6}{|c|}{ Historical Period, (Reference group 1980-1990) } \\
\hline From 1991 to 2000 & $\begin{array}{c}0.1170 \\
(0.0505)\end{array}$ & $\begin{array}{c}0.1730 \\
(0.0765)\end{array}$ & $\begin{array}{c}0.0036 \\
(0.1105)\end{array}$ & $\begin{array}{l}(0.1035) \\
(0.1040)\end{array}$ & $\begin{array}{c}0.2190 \\
(0.0895)\end{array}$ \\
\hline from 2001 to 2010 & $\begin{array}{c}0.2225 \\
(0.0645)\end{array}$ & $\begin{array}{c}0.3560 \\
(0.0960)\end{array}$ & $\begin{array}{c}0.0476 \\
(0.1405)\end{array}$ & $\begin{array}{l}(0.2710) \\
(0.1745)\end{array}$ & $\begin{array}{c}0.4665 \\
(0.1010)\end{array}$ \\
\hline Urban Area & $\begin{array}{c}0.0660 \\
(0.0870)\end{array}$ & $\begin{array}{c}0.0625 \\
(0.0875)\end{array}$ & $\begin{array}{c}0.0645 \\
(0.0875)\end{array}$ & $\begin{array}{c}0.0710 \\
(0.0875)\end{array}$ & $\begin{array}{c}0.0545 \\
(0.0870)\end{array}$ \\
\hline Male & $\begin{array}{c}0.1205 \\
(0.0420)\end{array}$ & $\begin{array}{c}0.1190 \\
(0.0420)\end{array}$ & $\begin{array}{c}0.1200 \\
(0.0420)\end{array}$ & $\begin{array}{c}0.1170 \\
(0.0420)\end{array}$ & $\begin{array}{c}0.1150 \\
(0.0420)\end{array}$ \\
\hline Rural Area (Before Enrollment) & $\begin{array}{l}(0.4605) \\
(0.0455)\end{array}$ & $\begin{array}{l}(0.3825) \\
(0.0655)\end{array}$ & $\begin{array}{l}(0.4590) \\
(0.0460)\end{array}$ & $\begin{array}{l}(0.4565) \\
(0.0460)\end{array}$ & $\begin{array}{l}(0.4535) \\
(0.0460)\end{array}$ \\
\hline Father's status ISEi AGE 16 & $\begin{array}{c}0.0065 \\
(0.0015)\end{array}$ & $\begin{array}{c}0.0065 \\
(0.0015)\end{array}$ & $\begin{array}{l}0.0045 \\
0.0020\end{array}$ & $\begin{array}{c}0.0065 \\
(0.0015)\end{array}$ & $\begin{array}{c}0.0065 \\
(0.0015)\end{array}$ \\
\hline Parent's Education & $\begin{array}{c}0.0460 \\
(0.0060)\end{array}$ & $\begin{array}{l}0.0460 \\
0.0060\end{array}$ & $\begin{array}{c}0.0460 \\
(0.0060)\end{array}$ & $\begin{array}{c}0.0300 \\
(0.0075)\end{array}$ & $\begin{array}{c}0.0455 \\
(0.0060)\end{array}$ \\
\hline Number of sibling & $\begin{array}{l}(0.0940) \\
(0.0150)\end{array}$ & $\begin{array}{c}(0.0940) \\
0.0150\end{array}$ & $\begin{array}{l}(0.0935) \\
(0.0150)\end{array}$ & $\begin{array}{l}(0.0935) \\
(0.0150)\end{array}$ & $\begin{array}{l}(0.0155) \\
(0.0195)\end{array}$ \\
\hline \multicolumn{6}{|c|}{ Interaction effects b/w variables \&historical periods } \\
\hline Before Enrollment 1991-2000 & & $\begin{array}{l}(0.0985) \\
(0.0960)\end{array}$ & & & \\
\hline Before Enrollment 2001-2010 & & $\begin{array}{l}(0.2245) \\
(0.1165)\end{array}$ & & & \\
\hline Father's status ISEI 1991-2000 & & & $\begin{array}{l}(0.0035) \\
(0.0030)\end{array}$ & & \\
\hline Father's status ISEI 2001-2010 & & & $\begin{array}{l}0.0055 \\
0.0040\end{array}$ & & \\
\hline Parent's Education 1991-2000 & & & & $\begin{array}{c}0.0305 \\
(0.0120)\end{array}$ & \\
\hline Parent's Education2001-2010 & & & & $\begin{array}{c}0.0580 \\
(0.0185)\end{array}$ & \\
\hline Number of sibling 1991-2000 & & & & & $\begin{array}{c}(0.3700) \\
0.0315\end{array}$ \\
\hline Number of sibling 2001-2010 & & & & & $\begin{array}{c}(0.2555) \\
0.0505\end{array}$ \\
\hline Constant Unit & $\begin{array}{l}(0.1825) \\
(0.1245)\end{array}$ & $\begin{array}{l}(0.2235) \\
(0.1270)\end{array}$ & $\begin{array}{l}(0.1145) \\
(0.1330)\end{array}$ & $\begin{array}{l}(0.0830) \\
(0.1285)\end{array}$ & $\begin{array}{l}(0.2555) \\
(0.1295)\end{array}$ \\
\hline $\begin{array}{c}\text { Sample Size } \\
\text { Pseudo } R^{2}\end{array}$ & $\begin{array}{c}1,463 \\
0.0790\end{array}$ & $\begin{array}{c}1,463 \\
0.0795\end{array}$ & $\begin{array}{c}1,463 \\
(0.0795)\end{array}$ & $\begin{array}{c}1,463 \\
0.0810\end{array}$ & $\begin{array}{c}1,463 \\
0.0805\end{array}$ \\
\hline
\end{tabular}

The result of model 1(noninteractive model) is consistent with the expected result, overall college education is going toward an expansion trend, dumb variable coefficient of two historical periods are positive, in next stage coefficient is larger, urban variables are not significant, which shows the aspect of entering college, male opportunities are higher than female, the opportunities in urban areas are higher than rural areas, father's occupation, and the parental education has positive significant effecting of admission for the children, finally have more number of brother and sisters have less chance of college admission, other factor keeps stable.

Model 2 tables 3 which shows the urban and rural inequality admission in different historical stages, It can be seen the interaction between 1991-2000, although the effect of opportunities in urban and rural areas is negative, but not significant, before 2001 two historical stages, shows that in urban and rural areas inequality has not changed significantly, 


\section{Unequal education opportunity in Pakistan for rural and urban areas and its evolution}

but the coefficient of interaction of domicile holder/ household resident between 2001 to 2010 are significant and negative, which indicates that after 2001 in the college studies, the chance of urban and rural areas inequalities have become more serious, as compared to from 1981 to 1990 , specifically in 1981 to 1990 enrollment of student in rural area have $27 \%\left(1-e^{-0.38}=0.267\right)$ lower entrance college enrollment as compared to urban areas, however, during the 2001 to 2010 to figure rose to $35 \%\left(1-e^{-0.38-0.22=0.352}\right)$.this result support assumption $2 \mathrm{~A}$.

Table 3 model 3 shows the result father ISIE, the historical stages of two interaction coefficients are not statically significant, by using the result of these coefficients can be judged, role of family status in last 3 decade after independence, there is no change in the opportunity to entering into the college.

Model 4 Table 3 shows the role of parents in the education of their children in college at the same time, the passage become more and more important because of the regression of the interaction between the variable and the dumb variable in two historical periods, the coefficients are positive and both are significant, specifically from 1981 to 1990 if increase the one year length in parental education, then the probability of children to entering college increased $3 \%\left(e^{0.030_{-1}=0.031}\right)$.In the subsequent two historical stages from 1991- 2000 and from 2001 to 2010 the figure rose up $8 \%$ $\left(e^{0.030+0.031_{-1-=0.066}}\right)$, continuous rise in the figure shows the influence of parental education. So the study shows the mechanism of the role of family culture capital, it have amore important role in education, and it also shows the equality of education, the phenomenon of inter reproduction is becoming more and more prominent, and the children of low family education are more likely to lose the opportunity to receive the education. Statically data support the assumption $2 \mathrm{C}$.

Table 3 model 5 shows the effect of number of brother and sisters; from 1991-2000 historical stage of dummy variable interaction effect is not significant, before 2001 data indicating no significant change in the role of variables. But the number of sibling and the historical stage with the dummy variable interaction is negative, this rose negative effect during this period indicating that have more number of sibling than the number of chances to entering into college is less, result shows that increase one number of brothers or sisters, then enrollment to college rates fell $6 \%\left(1-e^{-0.065=0.06}\right)$, and from 2001 to 2010 corresponding figure rose up to $18 \%$ (1$\left.e^{-0.065-0.158=0.18}\right)$. Assumption 2D is also confirmed.

Since 1981 in Pakistan, college enrollment class inequality has no significant change. Because of parental education and different number and brother and sister, an urban and rural inequality educational opportunity is in a rising trend.
Unequal educational opportunities of university and its evolution

The model of table 4 analysis the influence of variable on the university entrance opportunity and effect on the historical period, according to a new policy in the country, students also have to qualify the university entrance exam, but the contents of the entrance exam are not same as the high school or college contents and qualification.

Model 1 data shows enrollment in the university from 1981 to 2010 after 2001 a substantial increase in enrollment rate $45 \%$ $\left(e^{0.032_{-1}=0.46}\right)$ as compared to 1981 . According to expectation, technical school students are significantly lower enrollment, Gender domicile household variables of the regression coefficient are not significant. Historical period 1981-2010 indicating that opportunity of enrollment didn't increase towered university between the domicile holder/ local household, difference between gender, urban and rural areas, occupational status of the father, and parental education have a positive effect on their children's university education, at the end more number of brother and sister then have less chance of university entrance ${ }^{[15,16]}$.

Model 2 table 4 shows that in different historical stages, the unequal educational opportunities of universities between urban and rural area have changed, residences of rural area have less opportunity than the urban resident, other factors remain unchanged,

in the first historical period from 1991 to 2000 rural student $24 \%\left(e^{0.196}-1=0.24\right)$ less than urban students, in second historical stage there is no significant difference between urban and rural areas, the interaction was negative, shows that the rural student less likely interested in higher studies, rural residents probability $13 \%\left(1-e^{-0 . .19-0.36=0.131}\right)$ lower than as compared to urban students, this result shows the assumption in a rising trend, after 2001 higher education didn't expand as it should be, and at the same time, tuition fee, and other expenses have risen sharply, for university students to get job after graduation is not optimistic. 
Unequal education opportunity in Pakistan for rural and urban areas and its evolution

\begin{tabular}{|c|c|c|c|c|c|}
\hline \multicolumn{6}{|c|}{ Table 4} \\
\hline Variables & Model 1 & Model 2 & Model 3 & Model 4 & Model 6 \\
\hline \multicolumn{6}{|l|}{ (Reference group 1980-1990) } \\
\hline From 1991 to 2000 & $\begin{array}{c}0.3280 \\
(0.0750)\end{array}$ & $\begin{array}{c}0.3540 \\
(0.0930)\end{array}$ & $\begin{array}{c}0.4420 \\
(0.1765)\end{array}$ & $\begin{array}{l}0.5195 \\
0.1655\end{array}$ & $\begin{array}{c}0.3390 \\
(0.1345)\end{array}$ \\
\hline from 2001 to 2010 & $\begin{array}{c}0.6145 \\
(0.0830)\end{array}$ & $\begin{array}{c}0.7315 \\
(0.0980)\end{array}$ & $\begin{array}{c}0.5750 \\
(0.1790)\end{array}$ & $\begin{array}{l}0.5950 \\
0.2040\end{array}$ & $\begin{array}{l}0.7465 \\
0.1250\end{array}$ \\
\hline Before Enrollment ( In technical School) & $\begin{array}{l}(0.9635) \\
(0.0745)\end{array}$ & $\begin{array}{l}(0.9610) \\
(0.0750)\end{array}$ & $\begin{array}{l}(0.9595) \\
(0.0745)\end{array}$ & $\begin{array}{l}(0.9595) \\
(0.0745)\end{array}$ & $\begin{array}{l}(0.9630) \\
(0.0745)\end{array}$ \\
\hline Urban Area & $\begin{array}{l}(0.1245) \\
(0.1275)\end{array}$ & $\begin{array}{l}(0.1305) \\
(0.1280)\end{array}$ & $\begin{array}{l}(0.1250) \\
(0.1275)\end{array}$ & $\begin{array}{l}(0.1290) \\
(0.1275)\end{array}$ & $\begin{array}{l}(0.1390) \\
(0.1275)\end{array}$ \\
\hline Male & $\begin{array}{c}0.0875 \\
(0.0560)\end{array}$ & $\begin{array}{c}0.0830 \\
(0.0565)\end{array}$ & $\begin{array}{c}0.0860 \\
(0.0560)\end{array}$ & $\begin{array}{c}0.0875 \\
(0.0560)\end{array}$ & $\begin{array}{c}0.0840 \\
(0.0665)\end{array}$ \\
\hline Rural Area (Before Enrollment) & $\begin{array}{c}0.0350 \\
(0.0640)\end{array}$ & $\begin{array}{c}0.1965 \\
(0.1175)\end{array}$ & $\begin{array}{c}0.0365 \\
(0.0640)\end{array}$ & $\begin{array}{c}0.0340 \\
(0.0640)\end{array}$ & $\begin{array}{c}0.0460 \\
(0.0645)\end{array}$ \\
\hline Father's status ISEi AGE 16 & $\begin{array}{c}0.0035 \\
(0.0015)\end{array}$ & $\begin{array}{c}0.0035 \\
(0.0015)\end{array}$ & $\begin{array}{c}0.0040 \\
(0.0030)\end{array}$ & $\begin{array}{c}0.0035 \\
(0.0015)\end{array}$ & $\begin{array}{l}0.0035 \\
0.0015\end{array}$ \\
\hline Parent's Education & $\begin{array}{c}0.0455 \\
(0.0080)\end{array}$ & $\begin{array}{c}0.0470 \\
(0.0080)\end{array}$ & $\begin{array}{c}0.0460 \\
(0.0080)\end{array}$ & $\begin{array}{c}0.0535 \\
(0.0125)\end{array}$ & $\begin{array}{c}0.0455 \\
(0.0080)\end{array}$ \\
\hline Number of sibling & $\begin{array}{l}(0.1155) \\
(0.0230)\end{array}$ & $\begin{array}{l}(0.1155) \\
(0.0230)\end{array}$ & $\begin{array}{l}(0.1140) \\
(0.0230)\end{array}$ & $\begin{array}{l}(0.1440) \\
(0.0230)\end{array}$ & $\begin{array}{l}(0.0935) \\
(0.0355)\end{array}$ \\
\hline \multicolumn{6}{|l|}{$\begin{array}{l}\text { Interaction effects b/w variables \&historical } \\
\text { periods }\end{array}$} \\
\hline Before Enrollment 1991-2000 & & $\begin{array}{c}(0.0770) \\
0.1500\end{array}$ & & & \\
\hline Before Enrollment 2001-2010 & & $\begin{array}{l}(0.3500) \\
(0.1490)\end{array}$ & & & \\
\hline Father's status ISEI 1991-2000 & & & $\begin{array}{l}(0.0030) \\
(0.0040)\end{array}$ & & \\
\hline Father's status ISEI 2001-2010 & & & $\begin{array}{c}0.0010 \\
(0.0040)\end{array}$ & & \\
\hline Parent's Education 1991-2000 & & & & $\begin{array}{l}(0.0215) \\
(0.0170)\end{array}$ & \\
\hline Parent's Education2001-2010 & & & & $\begin{array}{c}0.0005 \\
(0.0195)\end{array}$ & \\
\hline Number of sibling 1991-2000 & & & & & $\begin{array}{c}0.0015 \\
(0.0490)\end{array}$ \\
\hline Number of sibling 2001-2010 & & & & & $\begin{array}{l}(0.1040) \\
(0.0580)\end{array}$ \\
\hline Constant Unit & $\begin{array}{l}(0.6275) \\
(0.1770)\end{array}$ & $\begin{array}{l}(0.6815) \\
(0.1820)\end{array}$ & $\begin{array}{l}(0.6610) \\
(0.2050)\end{array}$ & $\begin{array}{l}(0.6960) \\
(0.1925)\end{array}$ & $\begin{array}{l}(0.6690) \\
(0.1920)\end{array}$ \\
\hline Sample Size & 888 & 888 & 888 & 888 & 888 \\
\hline Pseudo $R^{2}$ & 0.1005 & 0.1020 & 0.1005 & 0.1005 & 0.1015 \\
\hline
\end{tabular}

Model 3 Table 4 shows the effect of Father ISEI on their children, two historical period coefficients of the interaction terms are not significant, indicating that positive effect, in different period children enrollment to the university is not changed because status of the family, so assumption 3B is not confirmed.

Table 4 model 4 shows that the parental educations have no significant effect on variables, during the historical stages, indicating that effect of variables is that there is no change in the university enrolment, so result doesn't support the assumption $3 \mathrm{C}$.
Model 5 of table 4 shows the Sibling's effect of opportunities to enter the university. In both historical period shows there is significant change. From 2001 to 2010 the interaction of variable coefficient is significant change. On each additional brother and sister the chance of entering the university declined $8.5 \%\left(1-e^{-0.0936}=0.0855\right)$. From 2001 to 2010 enter to the university chance declined almost $16 \%$ ( $1-$ $\left.e^{-0.093-0.104=0.163}\right)$. So, the result shows that increase in number and brother, have less opportunity to study in university, proves that assumption 3D is confirmed.

In short, from 1991 to 2000 there are no substantive changes in university enrollment opportunity inequality structure ${ }^{[14]}$. After 2001, in urban and rural areas educational inequality 
increased because different number of siblings and family culture capital.

\section{Conclusion}

Using data of research, analysis, combination of rational action theory, culture capital theory, and resource dilution theory, this research, examine inequality of education on three levels high school, college, and university, from 1981 to 2010 the inequality and its changing trends in rural and urban residence areas of Pakistan, this study found that in the high school stage, the education inequality between urban and rural areas and class hasn't changed. But inequality caused by family culture capital and the difference between numbers of siblings has been raised after 2001. Study shows after an independence analysis more than 30 years, result shows. However, education becomes more popular step by step. Still, the result didn't occur according to expectation, the unequal educational opportunities between different groups of high school students should be declined but it increased on some aspects. On college stage, there is no significant change on the class inequality of educational opportunities; in addition, after 2001 the inequality of education in urban and rural increased because increased different number of siblings, on the university stage there is also no significant change on the pattern of unequal opportunity from 1991-2000, in other words, the effect of various factor hasn't changed during this period, but after 2001 the inequality between rural and urban areas, and in the number of brother and sisters shows a significant expansion trend.

After the control other factors, although the father of ISEI shows positive significant affection at all educational levels. But its role hasn't changed since 1981, the class inequality pattern of education hasn't affected by education expansion [14], education policy and change in the macroeconomic structure. Data shows that in Pakistan society the relative education preferences or demand structures are comparatively stable, family culture capital, number of siblings are sensitive for education policy or macroeconomic environment. When cost of education is increased then expected return on education declined, when the rural resident have a low education family or the family of large siblings are more likely to give up education, because of limitation education resources, or lack of cultural capital. From this study in order to understand the inequality and its evaluation of Pakistan education since independence only focus on the class factor, which is not enough, still we need to pay attention to on such factors which influence the individuals or family education decision, so writer thinks rational action theory, culture capital theory and resource dilution theory should be more rational and practical.
The result of this paper shows three levels of education are not equal, especially in urban and rural areas, the expansion of equality and inequality in the number of children occurred almost all in $2001^{[15]}$. Since introducing the diffident education schemes, and scholarship by Punjab and federal government and sponsor policy for poor and brilliant students was a forward step toward expansion education. These policies-didn't show the effectual output on overall educational inequality. So, this how to promote education equality is still an important issue for decision-making departments and academic researchers in Pakistan.

\section{References:}

[1]. Section 9 of the Constitution (Eighteen Amendment) Act, 2010, inserted a new Art, 25A, after Art. 25 of the constitution (April 19, 2010) http://pakistanconstitutionlaw.com/18thamendment-2010/

[2]. "Educational stratification in Urban China : 19491994, Sociology of Education , Vol .71 , pp199122 ,

[3]. March , 1998 by Xueguang Zhou, P Meon and N. B Tuma.

[4]. The Forms of capital "in A. H. Halsaey et al. edition "Education culture, economy, and society, Oxford University Press, Page, 46-58 , 1997, new York, by P. Bourdieu.

[5]. Reproduction in education, society and culture. Beverly Hills, CA:Sage, 1977, by P.Bourdieu J.C.Passeron.

[6]. Cultural reproduction and social reproduction, "in J.Karabel and a. H.Halsey, eds., power and ideology in education, Oxford University Press, 1977, Pp.487-511, New York, by P.Bourdieu

[7]. Cultural capital in educational Research;A critical assessment "theoryAnd society, Vol.32, Page.567606

[8]. 2003, by weininger

[9]. Family size, and the quality of children, "Demography, Vol.18.Page.421-442, 1981 by J.Blake.

[10]. Family size, and the quality of children. Page .421442 , by J.Blake,

[11]. Explaining educational Differentials, Towards a formal rational action theory, "Rationality and society, Vol.9, Page .275-305 1997 by Richard Breen and J.H.Goldthorpe,

[12]. https://iqrapakonline.wordpress.com/tag/educationpolicy-pakistan/

[13]. http://www.moe.gov.pk/

[14]. A standard International Socio-economic Index of Occupational Status, Social Science Research, Vol. 
21 Page 1-56, 1992 by H.B.G Ganzeboom,P.M.De Graaf and D.J Treiman.

[15]. Change and stability in Education Stratification, American Sociological Review, Vol 46, Page 72-87, 1981 by R,D Mare
[16]. Conceptual and operational guidelines for the implementation of inclusive education, Special School as Resource Center, June 2005, Mr D Hindle,

[17]. http://www.education.gov.za/Portals/0/Documents/ Reports/Conceptual\%20and\%20Operational\%20Gu idelines2.pdf?ver=2008-03-05-104427-000 